\title{
Editorial
}

\section{Reacomodos en la derecha y la izquierda salvadoreñas}

El neoliberalismo ha sacudido las fronteras de los partidos políticos tradicionales, ocasionando cierto desconcierto en la sociedad. La derecha, comprometida con el ajuste y las reformas estructurales neoliberales, convencida de que la desigualdad es natural $y$, en consecuencia, de la inutilidad de cualquier esfuerzo para erradicarla; pero temerosa por haber ido demasiado lejos, promueve políticas orientadas a reducir su impacto social, así como también a generar consensos amplios, sin los cuales los cambios con dificultad podrán sostenerse a largo plazo. Esta postura, al mismo tiempo que la acerca a la izquierda política, la aleja de los sectores ideológicamente extremistas que militan en sus filas.

La izquierda política, por vocación consagrada a luchar por la igualdad o por las fórmulas que atenúan la desigualdad, convencida de que, en buena medida, ésta tiene raíz social $y$, por lo tanto, es erradicable, pero también preocupada - si no ansiosa - por ser objeto del reconocimiento de las fuerzas que deciden el destino del país y por dejar atrás su pasado revolucionario y militar, busca coincidencias con la derecha. Este acercamiento es comprensible y se justifica en nombre de la transición democrática y del consenso. Este desplazamiento de la izquierda hacia el centro derecha la aleja de sus posturas más conocidas, llegando al punto de cuestionar su identidad, $y$, al igual que en la derecha, hace que el sector más tradicional se aferre ideológicamente a los planteamientos de antaño, como si nada hubiese ocurrido después del final de la guerra fría.

Estos desplazamientos de la clase política de final de siglo causan asombro en no pocos y bastantes se sienten confundidos. Pareciera no haber diferencia entre la derecha y la izquierda y, por lo tanto, que la política ya no tiene sentido o, en el mejor de los casos, que ha cambiado tanto que se 
ha vuelto incomprensible. A comienzos de la década era más fácil, las posiciones estaban definidas con claridad meridiana y no era problema identificar de qué lado se encontraban los políticos. En la actualidad, las fronteras ideológicas que antes separaban e identificaban a unos y otros se han vuelto borrosas. El desconcierto que esta supuesta confusión proyectada por el espectro político pueda ocasionar influye, seguramente, en el desinterés de la mayoría de la población en la política.

En la páginas siguientes no se pretende tanto constatar los desplazamientos $y$ reacomodos efectuados por los políticos salvadoreños y sus efectos desconcertantes en la sociedad, los cuales, por otra parte, son evidentes, sino reflexionar sobre su significado y sus implicaciones.

\section{El pensamiento único de la derecha}

Contrario a las apariencias, la derecha no sólo cuenta con un plan - cuyos pilares fundamentales son la estabilidad macroeconómica, la desregulación, la reducción del Estado y la privatización de la propiedad estatal y las pensiones-, sino que no abriga la menor duda sobre su aplicación. Está convencida de que de su ejecución fiel dependen el desarrollo económico y el bienestar social de El Salvador. Por eso rehuye la verificación cuantitativa de las estadísticas del Programa de Naciones Unidas para el Desarrollo y se presente como verdad a priori.

El discurso pronunciado el 1 de junio por el presidente Armando Calderón en la asamblea legislativa ilustra esta creencia. Según el presidente de la república, El Salvador avanza "inexorablemente hacia la realización de su grandioso destino". Esto quiere decir que el plan, una vez lanzado, llevará al país de manera inequívoca a ese destino "grandioso", sin que nada ni nadie pueda impedirlo. Sin embargo, en ningún momento se describe el contenido de ese destino, impidiendo así comprender en qué consiste su grandiosidad. Sólo se refiere a él utilizando una fórmula genérica - "Nuestro nuevo El Salvador"—, sin especificar a quiénes — a cuántos—incluye ese "nuestro" ni en qué consiste la novedad.

La tesis central de este pensamiento único ya es de sobra conocida: el mercado gobierna y el gobierno administra lo que el mercado dicta. Es una ideología cerrada, que pretende poseer una representación total de la realidad,

A veces pareciera que esta novedad está definida por la modernidad, la democracia y la participación. Términos de uso corriente, en cuya definición no se profundiza, como si hubiera claridad y acuerdo general sobre su 


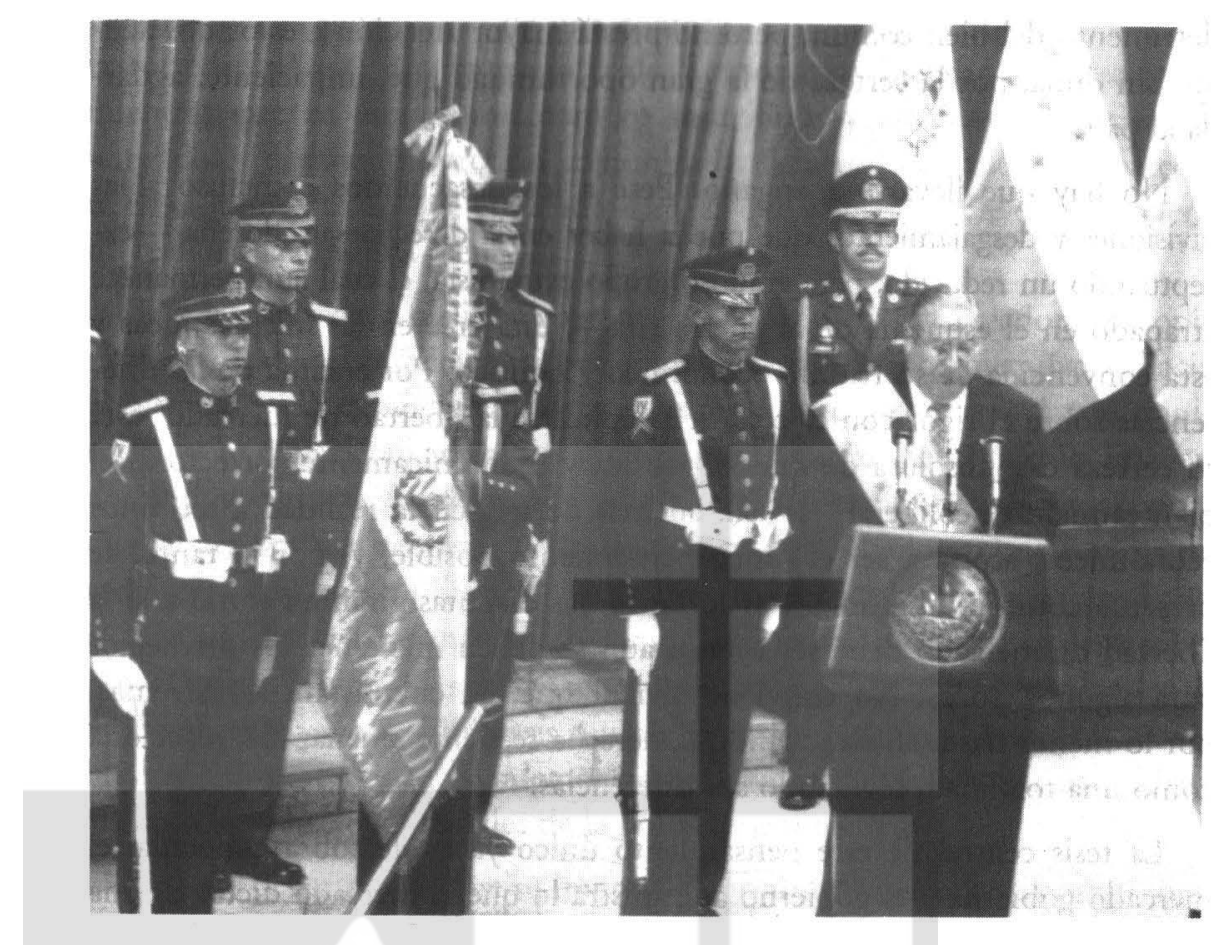

contenido. De todos modos, llama la atención que la equidad y la justicia no formen parte de la lista y hay que preguntarse por qué esta ausencia. Pero nada de esto parece importar a la derecha, porque El Salvador estaría predestinado por alguna fuerza superior desconocida a gozar de un destino grandioso. Visto así, es inevitable que el gobierno actual considere que sus fortalezas son mayores que sus debilidades.

Si El Salvador está predestinado a gozar de "oportunidades reales y maravillosas", es lógico invitar a acelerar el paso para llegar cuanto antes. Cualquier retraso no es más que una postergación innecesaria e inútil. En consecuencia, no hay que perder energias en "debates superficiales infructuosos", tampoco hay que distraerse "en cosas del pasado"; ni hay que permitir que "actitudes dubitativas" paralicen la marcha segura del país. No queda más que actuar con "determinación y sabiduría", "fortaleza y prontitud" para alcanzar una meta maravillosa.

El discurso asume gratuitamente que su visión de futuro, tan promisorio como vago e indefinido, es compartido por la sociedad. Da por descontado que el pals entero se comprometió con los acuerdos de paz, apostó por la democracia y acepta los planteamientos de la Comisión Nacional de Desarrollo para elaborar un plan de nación. Es cierto que no desconoce la existencia de temores y resistencias a los cambios impulsados, motivadas por enfoques políticos estrechos, ideologlas o intereses particulares egolstas, en 
detrimento del bien común; pero no presta mayor atención a estos obstáculos, sin duda, por la certeza de la gran oportunidad que, impaciente, aguarda al pais.

No hay que llevarse a engaño. Pese a los desacuerdos e incluso a las divisiones y desgajamientos que pueda haber en la derecha salvadoreña - exceptuando un reducido, pero ruidoso grupo extremista, el cual aún permanece atrapado en el esquema de la guerra fría-, ésta cree en las mismas ideas y está convencida de su triunfo económico y político. Por encima de las diferencias sobre el rigor con el cual deba aplicarse la libertad de mercado, está su certeza casi absoluta de que lo política y económicamente correcto es el planteamiento neoliberal, el cual, además de reducir la realidad a términos económicos, aspira a ser el único pensamiento posible, y, por lo tanto, se presenta como indiscutible. Por lo tanto, las disputas giran en torno a si la libertad de mercado debe ser total o aún se deben mantener los privilegios para algunos pocos. No conviene olvidar que, en circunstancias extremas, por lo menos hasta ahora, cuando la derecha se siente amenazada, reacciona como una totalidad, olvidando sus diferencias.

La tesis central de este pensamiento único ya es de sobra conocida: el mercado gobierna y el gobierno administra lo que el mercado dicta. Es una ideologia cerrada, que pretende poseer una representación total de la realidad, aunque a partir de una perspectiva exclusivamente económica, que asegura tener siempre la razón, prescindiendo de las circunstancias, y que presume que cualquier otro planteamiento debe inclinarse ante ella.

Los elementos más característicos de esta ideología son los siguientes: el mercado es el medio para resolver todos los problemas; las finanzas constituyen el motor de la economía; el libre intercambio ilimitado es factor de desarrollo ininterrumpido del comercio; la mundialización del mercado financiero y de la producción manufacturera lleva al desarrollo; la división internacional del trabajo modera las reivindicaciones sindicales; la moneda fuerte es factor de estabilización; la desregulación de la economía es condición indispensable de su crecimiento; el costo ecológico de éste es irrelevante; reducir el Estado es ampliar la civilización; el mercado lleva a la democracia; el pragmatismo reemplaza a la ideología; no ataca a los débiles, sino las pretensiones más débilmente justificadas; la corrupción es inevitable, pero será marginal; las desigualdades son de orden natural $y$, por lo tanto, constantes; primero hay que crear riqueza para luego repartirla; $y$ la experiencia económica chilena es el ejemplo que debe ser imitado.

Este planteamiento lleva aparejada la idea de una sociedad perfecta, en la cual predominaría la armonia. En ella no habría contradicciones significativas ni entre los individuos ni entre los grupos, sino que todos estarían dedicados a trabajar de manera equilibrada a favor de la transición democrática. Sin embargo, esta armonía no es perfecta aún. Su realización es obsta- 
culizada por la persistencia de una contradicción esencial entre el Estado y la sociedad. Aquél estarla plagado de funcionarios ineficaces y perversos, mientras que en ésta abundarían los individuos y empresarios eficientes, honrados y de gran proyección comunitaria. Esta contradicción desaparecerá en el momento en que el Estado haga lo que el mercado le dicte, haciendo realidad la armonía plena.

La ideología de la sociedad perfecta es estimulada por creadores de opinión, dedicados a publicitar la armonía social y el avance inequívoco hacia el bienestar y la democracia. Las contradicciones e inconsistencias se minimizan y se consideran intrascendentes para el gran diseńo final. La imagen de estos voceros de la perfección adquiere dimensiones desconocidas, porque, al arrogarse la representación de la sociedad, se colocan por encima de toda sospecha, quedan libres de cualquier crítica social y siempre proyectan el lado positivo en los medios de comunicación social, en los cuales aparecen continuamente. El servicio que estos voceros prestan al pensamiento único es muy valioso. El énfasis que su discurso pone en el avance inexorable hacia la prosperidad y la democracia vuelve más dificil poner en evidencia las contradicciones sociales de la política neoliberal.

En este pensamiento que se impone como único, ilusionado porque cree que no existe alternativa, es prácticamente imposible considerar el bien común, pues la medida de lo necesario, lo único y lo bueno la da el mercado. Este es la fuente del pensamiento único. Al relegar realidades como la solidaridad, la comunidad, etc., en favor de la competencia y el individualismo extremos, obliga a la población a aplicar el principio de supervivencia. La política ya no tiene como centro la persona y la sociedad, sino que su éxito o fracaso se determinan por los instrumentos que aplica. Si la derecha está interesada en rescatar la perspectiva del bien común debe abandonar $\longrightarrow$ al menos tornar cada vez más distancia - las formas de explotación y opresión y, en un mismo movimiento, debe descubrir los valores fundamentales de la convivencia humana. En ambos

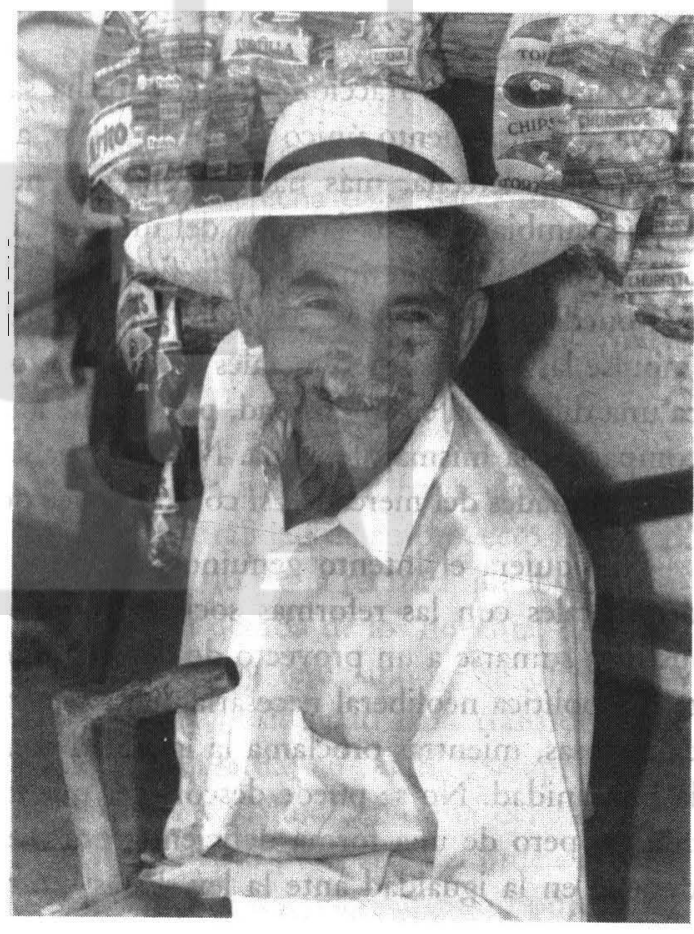


movimientos subyace un imperativo moral del cual ha prescindido hasta ahora.

Resulta, pues, dudosa la invitación a sumarse a este pensamiento único, y cuestionable la participación en la elaboración de un plan de nación donde, desde la perspectiva gubernamental, no parece existir otra alternativa. Pero es más cuestionable aún pensar que, asumiendo este pensamiento único y compartiendo sus falsas ilusiones, se puede seguir algún bien para las mayorías salvadorefias excluidas y empobrecidas, puesto que es, esencialmente, excluyente, tal como se puede comprobar en muchos paises del norte y del sur. Es indudable que ha llegado la hora para hacer a un lado los prejuicios, los recelos y los egoismos ancestrales, tal como la derecha lo reclama con toda razón; pero para buscar una alternativa a su pensamiento. Este no puede ser asumido como factor de cohesión y mucho menos como fuente inspiradora de entusiasmo. No deja de llamar la atención que, mientras otras naciones se esfuerzan por encontrar la forma para abandonar este planteamiento tan excluyente, en El Salvador, la derecha se emperia en adentrarse en él aún más.

El desafío principal que la derecha salvadoreña tiene planteado es su conversión a los intereses sociales y nacionales. Hasta ahora, se ha caracterizado por ir siempre a lo suyo, que es el enriquecimiento rápido e ilimitado.

Ninguna de las fracciones de la derecha salvadoreña actual ofrece alternativa al pensamiento único $y$, por lo tanto, a la exclusión. Es evidente que la extrema derecha, más nacionalista que neoliberal y para la cual nada habría cambiado desde la calda del muro de Berlín, no representa ninguna opción para la modernización de fin de siglo. En cambio, las alternativas que pueda ofrecer la derecha neoliberal son más atractivas. El que un grupo impulse las reformas neoliberales con más ortodoxia que el otro sólo significa una diferencia en intensidad, puesto que ambos absolutizan el mercado y comparten la misma ideologla. Ninguno habla con la misma insistencia de las debilidades del mercado asl como lo hace de las del Estado.

$\mathrm{Ni}$ siquiera el intento genuino para armonizar el ajuste y las reformas neoliberales con las reformas sociales y por construir un consenso básico justifica sumarse a un proyecto de derecha que no puede ser sino excluyente. La política neoliberal necesariamente genera desigualdades materiales escandalosas, mientras proclama la igualdad como derecho imprescindible de la humanidad. No se puede desconocer que la derecha neoliberal es democrática, pero de una forma deficiente, porque la igualdad que proclama se detiene en la igualdad ante la ley. Estas y otras contradicciones del pensa- 
miento único deben ser desveladas sin temor a romper falsos consensos. El consenso es importante como un medio que puede hacer la convivencia social posible $y$ tolerable, pero nunca debe ser convertido en un fin. Entonces, se vuelve una imposición más, muy útil para acallar la protesta de los excluidos y ocultar una realidad social escandalosa.

El desafio principal que la derecha salvadoreña tiene planteado es su conversión a los intereses sociales y nacionales. Hasta ahora, se ha caracterizado por ir siempre a lo suyo, que es el enriqueci-

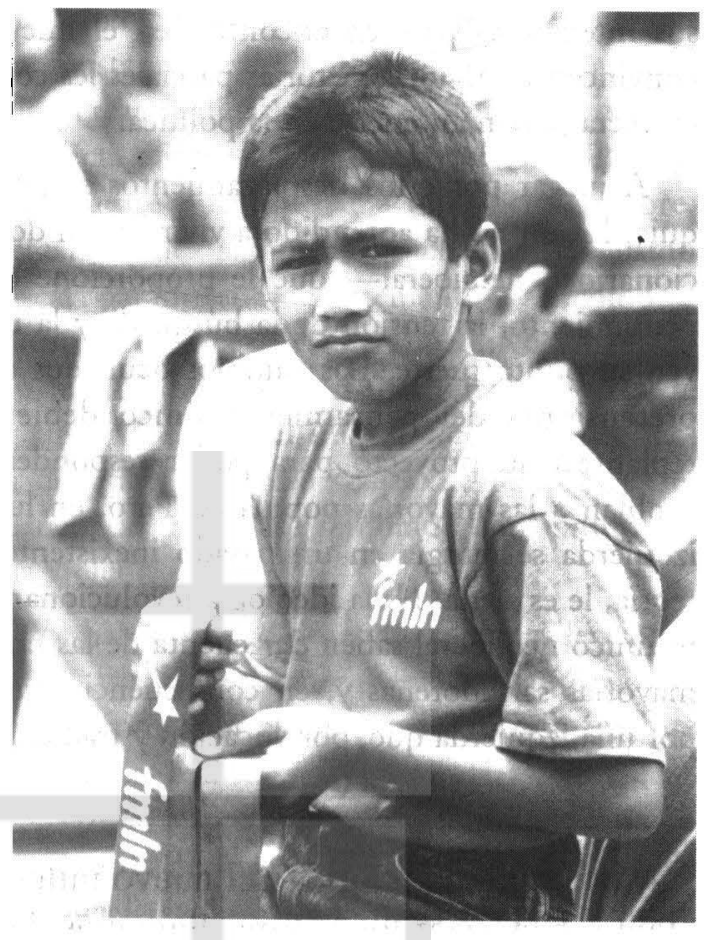
miento rápido e ilimitado. Las ideologlas sólo han sido un instrumento útil para ocultar la mercancía de contrabando. La derecha salvadoreña no fue liberal, sino que usó del liberalismo como más convino a su interés primordial. Ahora tampoco es neoliberal, sino que utiliza el pensamiento único porque sirve bien a sus intereses. No obstante esto, no está demás exigirle la revisión de su planteamiento económico y social, puesto que es evidente que no entrega lo que promete ni contribuye al desarrollo de El Salvador ni a su humanización. Para completar la tarea, la derecha debe hacer un esfuerzo enorme por desideologizarse, es decir, debe abandonar las racionalizaciones y los encubrimientos que le han permitido disimular ese afán de enriquecimiento sin importarle el costo social, durante la mayor parte del siglo XX.

\section{Las falsas expectativas de la izquierda}

La avalancha neoliberal desconcierta a la izquierda, hasta el extremo de llegar a poner en duda la racionalidad y moralidad de su proyecto histórico. Una parte se aferra a su pasado revolucionario y a la retórica que lo acompaf́aba, como si nada hubiese ocurrido en la década de los noventa, desconociendo la realidad actual, automarginándose y refugiándose en un mundo irreal, con lo cual se niega a sí misma la posibilidad para transformar el estado actual de cosas. Otra parte de la izquierda, en cambio, se aproxima a la derecha que favorece reformas sociales y la libertad plena del mercado, buscando así la aceptación y el reconocimiento por parte del orden establecido. Aunque este movimiento tiene mucho de pragmatismo oportunista, 
sus integrantes parecen encontrar en él nuevas seguridades y un discurso convincente. Algunas victorias parciales les confirman que ésta es la postura correcta para mantenerse en la política.

A juzgar por estos desplazamientos sorprendentes, pareciera que la izquierda aún no ha aprendido a vivir sin un dogma - ya sea de corte revolucionario o neoliberal- que le proporcione certezas. La independencia de pensamiento, la tensión de la búsqueda y la ilusión del futuro no constituyen su punto fuerte. Los cambios ocurridos después de la guerra fría y las pretensiones del pensamiento único debieran impulsarla a repensar y replantear su proyecto para poder responder a las cuestiones vitales que agobian a las mayorías populares. Pero, en lugar de asumir este desafio, la izquierda se refugia en un pasado inexistente o en una ideologia que, en teorla, le es ajena. Ni la ideología revolucionaria del pasado ni el pensamiento único neoliberal saben dar cuenta de las necesidades y aspiraciones de las mayorías salvadoreñas $y$, en consecuencia, tampoco debieran ser asumidos por una izquierda que, por vocación y tradición, se debe a éstas.

A la izquierda política del nuevo milenio le corresponde, por lo tanto, historizar los valores humanos del socialismo a partir de la crítica a las experiencias históricas del siglo XX.

El pensamiento de izquierda en cuanto tal es incompatible con la desigualdad y con cualquier forma de explotación y opresión. Su compromiso con la libertad, la igualdad y la solidaridad debiera inspirar la crítica de la realidad existente y animar la acción para transformarla. La izquierda se encuentra en una posición ventajosa respecto a la derecha, pues no tiene que descubrir estos valores que, en sí mismos, implican una crítica al capitalismo, en cualesquiera de sus versiones, y una voluntad transformadora. Sin embargo, debe renovar su compromiso, ensombrecido por el desconcierto provocado por los acontecimientos posteriores a la caída del muro de Berlin y el neoliberalismo. Estos la desafian a historizar de nuevo el valor de la justicia social, asl como ya lo hizo en las dos últimas décadas. Las limitaciones de esta historización y su fracaso en cuanto que no condujo al triunfo esperado no la excusan para volver a intentarlo. Las circunstancias históricas no son las mismas, pero la explotación y la opresión no han desaparecido - ni siquiera han disminuido, sino que han adquirido otras formas. De ahí la exigencia de una nueva historización. No es un desafío que se puede tomar o dejar. La izquierda está obligada a asumirlo, si quiere abrirse al futuro.

Historizar no significa rechazar el diálogo o el debate con la derecha, tampoco implica cerrarse a negociaciones o pactos, cuando asl convenga a los intereses de las mayorías. En las circunstancias actuales, historizar signifi- 
ca, negativamente, no dejarse arrastrar por el pensamiento único neoliberal, sino ejercer una función crítica constante desde la libertad, la igualdad y la solidaridad. Positivamente, exige crear realidades que respondan cada vez más -y no siempre de forma directa e inmediata - a estos valores. Proponer su vigencia absoluta o creer que se puede llegar a una sociedad libre, igualitaria y solidaria de manera mecánica significaría caer en el idealismo ineficaz o pensar que la utopía está garantizada de antemano -así como lo cree la derecha, para la cual la historia avanza de manera inequívoca hacia la prosperidad y el bienestar. La izquierda debiera saber más y mejor acerca de la complejidad de los procesos históricos, la cual impide que el avance tecnológico conduzca de manera directa al progreso social. La fe ciega en el triunfo final de una ideología suele dejar su paso sembrado con innumerables víctimas del hambre y de la violencia.

La izquierda todavía no parece haber aprendido estas dolorosas lecciones del pasado. Después de las desautorizaciones experimentadas tanto por el dogma comunista del este europeo como por el dogma del triunfo final de las revoluciones centroamericanas, no es realista volver a refugiarse en creencias dogmáticas de ningún tipo. Por la misma razón, el pensamiento único neoliberal debe ser descartado; aparte de que es evidente que no puede entregar lo que promete. El potencial revolucionario de la izquierda radica en su vocación a construir la convivencia humana, confrontando la avalancha neoliberal.

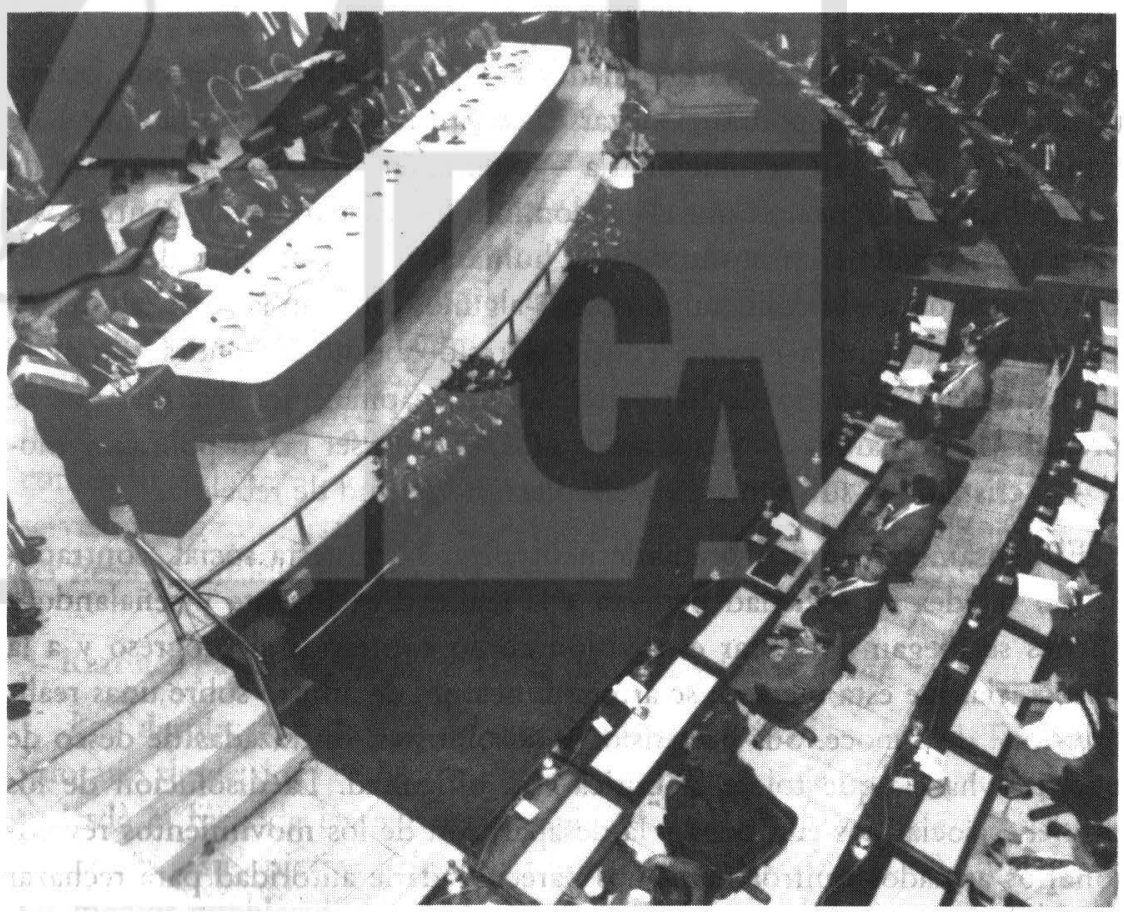


A la izquierda política del nuevo milenio le corresponde, por lo tanto, historizar los valores humanos del socialismo a partir de la crítica a las experiencias históricas del siglo XX. El concepto de socialismo debe ser liberado de su asociación a los regímenes del este europeo y a la socialdemocracia y, al mismo tiempo, debe rescatar su dimensión humana más auténtica. Eliminar el concepto del discurso para no perturbar al orden establecido no resuelve la dificultad, aunque, sin duda, es muy cómodo para quienes buscan la aceptación del poder económico; olvidar los valores de libertad, igualdad y solidaridad que invoca, equivaldría a desnaturalizar la izquierda. Aunque no habría por qué temer el uso apropiado del término socialismo, la cuestión no es tanto ésta como la voluntad transformadora global de una realidad excluyente y violenta, que ofrezca una alternativa real al pensamiento único neoliberal.

Este desafío no es sólo de orden intelectual, sino que al ser una posibilidad real invita a comprometerse con una lucha inclaudicable. Es una lucha que incluye la generación de una conciencia nueva que impulse a desenmascarar y combarir la perversidad neoliberal y a construir una sociedad más humana -y cristiana. A este esfuerzo deben sumarse trabajadores, comunidades de base, intelectuales y sobre todo las iglesias cristianas, cuya misión las obliga a comprometerse con la justicia social. La deshumanización que predomina en todas partes es una interpelación ineludible para una Iglesia que se define a sí misma como "experta en humanidad". Renunciar a la utopía bíblica y contemporizar con el neoliberalismo tiene mucho de cooptación y muy poco de evangélico.

Luchar por la libertad, la igualdad y la solidaridad sin saber con exactitud cuándo o cómo podrán realizarse, constituye una aventura moral de inspiración netamente revolucionaria - y también cristiana-, que nace de una profunda indignación por el predominio destructivo de sus contrarios y de un amor igualmente profundo a la humanidad $-y$ al reino de Dios. El "horror económico" neoliberal, tal como algunos califican la sociedad del 20 por ciento que tendrá empleo contra el resto que no lo tendrá y, por lo tanto, quedará excluido de los beneficios del capitalismo, hacia la que se aproxima la humanidad a pasos acelerados, debiera ser razón política y moral - y cristiana - suficiente para adoptar una actitud de rebeldia.

El pensamiento único pretende neutralizar la protesta social, contraponiendo su idea de sociedad perfecta a la realidad excluyente y seńalando a quienes se niegan a aceptar esta visión como contrarios al progreso y a la democracia. De esta manera, se arroga funciones de árbitro sobre unas realidades que desconoce. Sus pretensiones absolutistas, disfrazadas de deseo de consenso, hacen que tolere la critica con dificultad. La disolución de los regimenes socialistas europeos y la desaparición de los movimientos revolucionarios armados centroamericanos pareciera darle autoridad para rechazar 
cualquier alternativa que no sea la suya. Renunciar a la utopía socialista en razón de sus primeros fracasos históricos significaria echar por la borda el sentido social y moral de la izquierda. El reclamo de la derecha por la tenacidad de la rebeldía ante la imposición, la injusticia y la violencia no debe ser óbice para exigir con firmeza los cambios estructurales necesarios para eliminar estos males sociales.

Plantear la cuestión de la sociedad utópica, en la cual se concreticen los valores fundamentales que hacen humana la convivencia, admitiendo que es más lo que no se sabe que lo que se sabe sobre ella y que buena parte de ello no puede ser conocido a priori, es crucial para criticar la existente y para delimitar el horizonte en el cual hay que actuar. La utopía sólo puede proporcionar un esbozo general, pero necesario, de la realidad hacia la cual hay que tender. La práctica transformadora irá dando respuesta a las interrogantes planteadas en la actualidad y, a su vez, planteará otras nuevas, no previstas ahora. Por lo tanto, a la utopía no puede exigírsele más de lo que puede dar de sí. Pero sin ella no es posible superar el pensamiento único neoliberal.

La misión de la izquierda es otra. Guiada por el convencimiento de que la desigualdad y la exclusión tienen una razón social y, por lo tanto, son eliminables, debiera concentrar su esfuerzo en desenmascarar la retórica del discurso dominante, buscar alternativas al pensamiento único y mostrar las contradicciones de la sociedad neoliberal.

La incertidumbre sobre el presente y el futuro no debiera paralizar a la izquierda. La aparente ausencia de alternativa al neoliberalismo actual debiera ser un acicate para criticar la falsedad de la solución que ofrece y para construir otra más incluyente y humana. El futuro está abierto para la izquierda, siempre y cuando no transija en sus valores fundamentales y sepa historizarlos, aun a contracorriente. Pero para ello, debe estar dispuesta a comenzar de nuevo cuantas veces sea necesario, superando la tentación conservadora de quedarse en lo conocido o conformarse con lo adquirido. Para ser fiel a su misión, la izquierda debe ser revolucionaria consigo misma.

\section{Razones para diferenciar entre la derecha y la izquierda}

Los desplazamientos de la derecha y la izquierda salvadoreña pueden valorarse desde dos perspectivas: desde los intereses de cada partido político y desde el bien de las mayorlas populares. Las decisiones de los primeros obedecen a su objetivo primordial que es alcanzar el poder del Estado por los medios establecidos en la ley. De ahl que los polf́ticos tiendan a pensar 
equivocamente que todo les está permitido, lo cual con frecuencia los coloca en la ilegalidad y el fraude. En la práctica, ninguna nación está libre de la corrupción ni del fraude político, pero éstos son más frecuentes ahl donde la institucionalidad estatal y la conciencia colectiva son más débiles. Desde esta perspectiva, es poco lo que cabe señalar o reclamar a los partidos políticos, excepto lo establecido por la ley.

En cambio, el bien de las mayorfas populares ofrece una perspectiva muy diferente para valorar estos movimientos ideológicos. En consecuencia, no es nada despreciable que la derecha se muestre interesada en complementar el carácter exclusivamente económico de su proyecto de nación con reformas sociales y admita, al menos en teorla, la participación de la población en las decisiones importantes (ver "Deficiencia en sociedad", ECA, 594, 1998). Hay que otorgar el beneficio de la duda a esta derecha que al fin parece haberse convencido de que la libertad — que asegura conocer biendebe ser complementada con la igualdad y la solidaridad. Esta apertura debiera ser aprovechada para animarla a seguir adelante, trabajando por el bienestar de las mayorias salvadorehias. En este contexto, se le hace un gran servicio si se le sefialan sus contradicciones ideológicas. La prosperidad económica y la democracia promeridas no pueden posponerse de manera indefinida, postergándolas a una especie de final escatológico. Si el capitalismo tiene rostro humano, hay que exigir sin dilación su aparecimiento. Si dicho rostro no surge en un tiempo prudencial, entonces, es evidente la necesidad de un replanteamiento radical del mismo. La validez de una ideología cuyo argumento más sólido consista en predecir tiempos mejores depende de la verificación de sus predicciones.

Ahora bien, la apertura de la derecha a las reformas sociales y la participación ciudadana no puede ser utilizada por la izquierda como pretexto para renunciar a su vocación liberadora sin desnaturalizarse. Una cosa es animar a la derecha $\longrightarrow$ incluso apoyarla, si se considera conveniente para los intereses populares - en su intento por descubrir la igualdad y la solidaridad; pero otra bien distinta es renunciar a la propia identidad para ser aceptado por ella y así tener más posibilidades para ganar unas elecciones o poder social. Mientras la izquierda mantenga sus principios básicos, la derecha no la aceptará. Más aún, la derecha salvadoreña actual no tiene la grandeza de ánimo necesaria como para aceptar a una izquierda que la consideró enemiga de clase y le declaró la guerra. Eso para no hablar de poderosos prejuicios raciales y de clase.

El interés de la derecha en la izquierda salvadoreña tiene más de cooptación que de un interés genuino por lo que ésta pudiera aportar al proceso de construcción de una nación próspera y democrática. Obedece más a la dinámica del pensamiento único, tan convencido de sus creencias, que no tolera alternativa. Es una exigencia de la idea de sociedad perfecta, 
cuyo triunfo sería confirmado por la integración de la izquierda. Por consiguiente, en la medida en que la izquierda sea cooptada por la derecha pierde su razón de ser. Es una ingenuidad calcular que la igualdad y la justicia pueden ser pactadas con la derecha, por más democrática que ésta se presente. En estas condiciones, el triunfo electoral tampoco tendría sentido, porque una izquierda que llegase al poder para aplicar los principios del pensamiento único de una manera ortodoxa -eliminando los monopolios, los oligopolios y los privilegios-, haría un gobierno de derecha, todo lo moderna que se quiera, pero de derecha, al fin de cuentas. Cabe preguntarse, entonces, qué sentido podrla tener una izquierda dedicada a gerenciar un proyecto eminentemente capitalista; ésa es, justamente, una tarea de la derecha que, si se lo propone, lo puede hacer bastante bien.

La misión de la izquierda es otra. Guiada por el convencimiento de que la desigualdad y la exclusión tienen una razón social y, por lo tanto, son eliminables, debiera concentrar su esfuerzo en desenmascarar la retórica del discurso dominante, buscar alternativas al pensamiento único y mostrar las contradicciones de la sociedad neoliberal. Proponerse arrebatar al capital financiero las prioridades del debate nacional no es una quimera. Pero para ello, la izquierda debe mantenerse fiel a sus principios y apuntar hacia la utopla de talante humanista que la ha caracterizado. El compromiso con la realidad humana negada por el neoliberalismo debiera animar su pensamiento y su praxis, asumiendo con valentia el desafio para encontrar las respuestas exigidas por la sociedad.

En la práctica, ninguna nación está libre de la corrupción ni del fraude político, pero éstos son más frecuentes ahí donde la institucionalidad estatal y la conciencia colectiva son más débiles.

Tal vez ya no pueda predecir con la misma seguridad de antes el futuro de la humanidad, pero si puede señalar con bastante certeza que la alternativa neoliberal no satisfará las expectativas que ella misma ha planteado. A partir de la crítica a la imposición, la desigualdad y al egolsmo capitalistas podría crear nuevas posibilidades reales, más justas y solidarias. Antes que ser un partido político, la izquierda debe ser un movimiento profético y utópico, que genere conciencia colectiva y movilice a las mayorías empobrecidas. Sólo así podrá ser el partido de las mayorías y tener el poder necesario para ganar elecciones, porque sólo asI tendrá la fuerza y la mística necesarias para ello.

Los reclamos de la derecha por los sobresaltos que pudiera protagonizar en este empeño no debieran atemorizarla. Su mejor garantía son su potencial revolucionario y sus convicciones democráticas. La sociedad salvadoreña 
no es perfecta ni avanza con la determinación y seguridad que sus epígonos aseguran, sino que está atrevasada por contradicciones de toda clase, las cuales deben ser arbitradas por el Estado, desde la perspectiva del bien común. Un bien que, a veces, puede exigir el mal de algunos. Desentenderse o negar estas contradicciones no las resuelve. Señalarlas y presionar para que sean enfrentadas con realismo no implica rechazar la transición ni la democracia, tal como parecen implicar equivocamente los promotores del pensamiento único, sino impulsar con ahínco el esfuerzo transformador.

Quizás ésta no sea la mejor postura para ganar las elecciones -al menos no tan pronto como la izquierda quisiera-, pero es la mejor opción desde una perspectiva política y ética- para defender el derecho a la vida de la mayoría de los salvadoreños, un derecho amenazado, si no negado, por fuerzas muy poderosas. Evidentemente, la izquierda no es la fuerza más idónea para administrar el capitalismo, pero sí lo es para promover y defender la humanidad de la sociedad salvadoreña. Entre hacer mal lo que la derecha puede hacer bien y asumir el papel de defender los valores humanos desde la oposición política, la opción de la izquierda es clara. Frente a las pretensiones totalitarias del pensamiento único y los intentos encubridores de su idea de sociedad perfecta es necesaria una oposición firme y valiente, comprometida con la defensa del derecho a la vida de los salvadoreños. Dicho con otras palabras, antes que ser un mal gobierno es mejor ser una buena oposición y esto no sólo por mera conveniencia política, sino sobre todo por razones morales.

La izquierda salvadoreña tiene, además, una deuda con los caídos durante el conflicto armado. Decenas de miles de militantes y simpatizantes se enrolaron en su lucha motivados por un genuino deseo de justicia y solidaridad y cayeron soñando con una sociedad más humana y fraterna. Muchos de los políticos actuales, entonces dirigentes rebeldes, los motivaron con sus ideas y su ejemplo a abandonarlo todo para consagrarse a este ideal. La deuda adquirida con estas víctimas de la guerra no se salda sólo con un monumento que recuerde su memoria, sino también y en especial trabajando incansablemente por el ideal al que entregaron su juventud y su vida.

San Salvador, 25 de junio de 1998. 